\title{
Differences in the metabolism of esterified and unesterified linoleic acid by rumen micro-organisms
}

\author{
By J. H. MOORE, R. C. NOBLE, W. STEELE AND J. W. CZERKAWSKI \\ Hannah Dairy Research Institute, Ayr \\ (Received ${ }_{24}$ March 1969-Accepted 19 7 Hne 1969)
}

\begin{abstract}
I. Sheep were given intraruminal infusions of maize oil or linoleic acid and samples of contents were taken from the rumen and abomasum at different times after the infusions. Hydrolysis of the maize oil occurred in the rumen with the production of mono- and diglycerides as intermediates. Linoleic acid derived from the maize oil was hydrogenated to stearic acid. When linoleic acid was infused into the rumen, little or no stearic acid was produced and octadecenoic acid accumulated.

2. When linoleic acid or maize oil was incubated with rumen contents in an artificial rumen and samples of the reaction mixtures were taken from the apparatus after various time intervals, the results were similar to those obtained in vivo, except that the hydrolysis of maize oil did not give rise to mono- and di-glycerides.

3. These results are discussed in relation to previous findings on the effects of intraruminal infusions of maize oil or linoleic acid on the fatty acid composition of the blood triglycerides of sheep.
\end{abstract}

Previous work (Noble, Steele \& Moore, 1969) showed that when sheep were given intraruminal infusions of linoleic acid, the effect on the fatty acid composition of the blood triglycerides depended on whether the linoleic acid was infused in free or esterified form. The increase in the concentration of linoleic acid in the plasma triglycerides observed after the intraruminal infusion of maize oil was considerably less than that observed after an equivalent amount of linoleic acid was infused into the rumen. Furthermore, after linoleic acid was infused into the rumen, the transient increase in the concentration of linoleic acid in the plasma triglycerides was followed by an increase in the concentration of oleic acid. On the other hand, after maize oil was infused into the rumen, the transient increase in the concentration of linoleic acid in the plasma triglycerides was followed by an increase in the concentration of stearic acid. It was suggested that these different effects on the fatty acid composition of the plasma triglycerides might be due to the fact that the rumen micro-organisms were able to hydrogenate linoleic acid more efficiently when it was administered in triglyceride form than when it was administered as the free acid. It was decided therefore to investigate the metabolism of linoleic acid in the rumen of sheep after they had been given intraruminal infusions of maize oil or linoleic acid. In addition, experiments were carried out in which maize oil or linoleic acid was incubated with rumen contents in vitro.

\section{EXPERIMENTAL}

\section{Experiments in vivo}

Animals and diets. Two adult wether sheep of the Hampshire breed, each with permanent rumen and abomasal fistulas and each weighing about $65 \mathrm{~kg}$, were housed 
in individual metabolism cages. The sheep were given $900 \mathrm{~g}$ hay/day in two equal portions, one at $07.00 \mathrm{~h}$ and the other at $17.00 \mathrm{~h}$. Water was given ad lib.

Procedure. The sheep were given the diet of hay for 28 days. An emulsion of $40 \mathrm{~g}$ of maize oil was infused at constant rate into the rumen of one of the sheep between 09.00 and $10.00 \mathrm{~h}$ on day 29 . On the same day, an emulsion of $40 \mathrm{~g}$ of 'linoleic' acid, obtained from Price's (Bromborough) Ltd, Bebington, Cheshire, was infused into the rumen of the other sheep, also between 09.00 and ro.00 h. Both emulsions were prepared and infused as described previously (Moore, Noble \& Steele, 1968). The weight percentages of the major fatty acids in the maize oil were $16: 0,9 \cdot 9 ; 18: 0,2 \cdot 1$; I $8: 1,22 \cdot 9 ; 18: 2,64.4$ : the weight percentages of the major fatty acids in the "linoleic" acid were $16: 0,15 \cdot 2 ; 18: 0,2 \cdot 2 ; 18: 1,10 \cdot 9 ; 18: 2,71 \cdot 1$. With the apparatus described by Czerkawski (1966), samples of rumen and abomasal contents were taken from the sheep immediately before and at various time intervals (see Tables I-3) after the infusions had begun. Hay was withheld from the sheep until after the last samples of rumen and abomasal contents had been taken.

Extraction of lipids and methods of analysis. The lipids were extracted from the rumen and abomasal contents according to the method described by Moore \& Williams (1963). The extracted lipids were fractionated by thin-layer chromatography on plates of silica gel G (E. Merk, A.G., Darmstadt, Germany) using a solvent system of hexane-diethyl ether-formic acid (80:20:I, v/v). The fatty acid compositions of the lipid fractions were determined by the methods reported previously (Moore et al. 1968).

\section{Experiments in vitro}

Apparatus and incubation procedure. The artificial rumen used in these experiments and the general experimental procedures have been described in detail by Czerkawski \& Breckenridge (I969). Strained rumen contents (Czerkawski \& Breckenridge, I969) were obtained from a sheep that had been maintained on a diet consisting of $0.5 \mathrm{~kg}$ sugar-beet pulp and $0.5 \mathrm{~kg}$ hay/day. Three incubation vessels were used and each contained $200 \mathrm{ml}$ of artificial saliva (McDougall, I948) and $100 \mathrm{ml}$ of an aqueous solution containing $\mathrm{I} \cdot 5 \mathrm{~g}$ of sucrose and $200 \mathrm{mg}\left(\mathrm{NH}_{4}\right)_{2} \mathrm{CO}_{3}$. After the apparatus had been gassed with $5 \% \mathrm{CO}_{2}$ in $\mathrm{N}_{2}, 200 \mathrm{ml}$ of strained rumen contents were added to each vessel. After incubation for $30 \mathrm{~min}$, the following were added: to vessel I (control), $20 \mathrm{ml}$ of $\mathrm{I} \%(\mathrm{w} / \mathrm{v})$ Tween 80 (polyoxyethylene sorbitan mono-oleate; obtained from Honeywill \& Stein Ltd, London); to vessel 2, $20 \mathrm{ml}$ of an emulsion of $200 \mathrm{mg}$ 'linoleic' acid in $\mathrm{I} \%$ Tween 80 ; to vessel $3,20 \mathrm{ml}$ of an emulsion of $180 \mathrm{mg}$ maize oil in $\mathrm{I} \%$ Tween 8o. The 'linoleic' acid and maize oil were as described above. Incubations were carried out at $39^{\circ}$ and samples $(5 \circ \mathrm{ml})$ of the reaction mixture were taken from each vessel immediately, and at $1 \cdot 5,3,5$ and $7 \mathrm{~h}$ after the additions of Tween 80 or the lipid substrates.

Methods of analysis. The lipids were extracted from the samples of reaction mixture and were analysed by the methods described above. In addition, quantitative thin-layer chromatography was carried out by including $n$-heptadecanoic acid as an internal standard. 
RESULTS

\section{Experiments in vivo}

Infusion of maize oil. Fig. $\mathrm{I} a$ and $b$ are tracings of thin-layer chromatograms of samples of the lipids extracted from the rumen and abomasal contents before and at various times after infusion had begun. The lipids obtained from the rumen and abomasal contents before infusion began contained appreciable proportions of unesterified fatty acids but only very small proportions of glycerides. As might be expected, tri-, di- and mono-glycerides constituted a considerable proportion of the lipid in the sample taken from the rumen immediately after infusion had ceased (Fig. I $a$ ). As the time after infusion increased, the proportions of glycerides in the lipid extracted from the rumen contents decreased, but even after $8 \mathrm{~h}$ triglycerides still accounted for an appreciable proportion of the rumen lipid. The composition of the lipids in the rumen contents $24 \mathrm{~h}$ after infusion had begun appeared to be very similar to that observed before the sheep was given the infusion. The proportions of tri-, di- and mono-glycerides in the lipids extracted from the abomasal contents did not increase until $3 \mathrm{~h}$ after infusion had begun, but thereafter the proportions of glycerides decreased considerably (Fig. I $b$ ).

Table I. Fatty acid compositions (major components, weight percentages of the total) of the lipids in the contents of the rumen after the sheep had been given an intraruminal infusion of maize oil

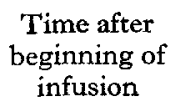

infusion

(h)

0
$x$
2
3
4
6
8
24

\begin{tabular}{|c|c|c|c|}
\hline \multicolumn{4}{|c|}{ Total lipid } \\
\hline I6:0 & $18: 0$ & I 8: I & $18: 2$ \\
\hline $25 \cdot 3$ & $37 \cdot I$ & $6 \cdot 5$ & 3.2 \\
\hline $12 \cdot 7$ & $5 \cdot 5$ & $25 \cdot 1$ & $52 \cdot 7$ \\
\hline $20 \cdot 6$ & $17 \cdot 7$ & $170^{\circ}$ & 297 \\
\hline $2 I \cdot 2$ & $18 \cdot 1$ & 17.7 & 27.4 \\
\hline 16.9 & 20.5 & $20 \cdot 5$ & $26 \cdot 0$ \\
\hline 19.2 & $28 \cdot 3$ & 18.4 & 19.3 \\
\hline 19.0 & $3^{8 \cdot 0}$ & $I_{5} \cdot I$ & 13.0 \\
\hline $20 \cdot 3$ & $52 \cdot 1$ & $7 \cdot 5$ & 3.9 \\
\hline
\end{tabular}

\begin{tabular}{|c|c|c|c|}
\hline \multicolumn{4}{|c|}{ Triglycerides } \\
\hline I6:0 & 18:0 & I8: I & $18: 2$ \\
\hline \multicolumn{4}{|c|}{ No sample } \\
\hline I 15 & $2 \cdot 4$ & $27 \cdot 9$ & $58 \cdot 0$ \\
\hline $12 * 3$ & 4.0 & $27 \cdot 5$ & 54.2 \\
\hline $12 \cdot 8$ & $5 \cdot 2$ & $26 \cdot 9$ & 53.7 \\
\hline 15.6 & 5.0 & $27 \cdot 6$ & $50 \cdot 2$ \\
\hline 16.6 & $6 \cdot 1$ & $28 \cdot 1$ & $47 \cdot 3$ \\
\hline $16 \cdot 2$ & 6.4 & $28 \cdot 2$ & $46 \cdot 1$ \\
\hline $28 \cdot 3$ & $17 \cdot 6$ & 23.9 & $24 \cdot 8$ \\
\hline
\end{tabular}

\begin{tabular}{rrrr}
\multicolumn{3}{c}{ Unesterified fatty acids } \\
$\overbrace{16: 0} 18: 0$ & $18: 1$ & $18: 2$ \\
$19 \cdot 2$ & $65 \cdot 7$ & $7 \cdot 7$ & $2 \cdot 8$ \\
$19 \cdot 5$ & $50 \cdot 6$ & $10 \cdot 1$ & $7 \cdot 4$ \\
$20 \cdot 1$ & $53 \cdot 0$ & $10 \cdot 9$ & $7 \cdot 1$ \\
$18 \cdot 6$ & $59 \cdot 7$ & $10 \cdot 4$ & $2 \cdot 3$ \\
$18 \cdot 2$ & $59 \cdot 5$ & $10 \cdot 8$ & $1 \cdot 9$ \\
$17 \cdot 7$ & 60.9 & $11 \cdot 4$ & $1 \cdot 3$ \\
$17 \cdot 5$ & 67.2 & $7 \cdot 2$ & $1 \cdot 6$ \\
15.4 & $73 \cdot 8$ & $4 \cdot 1$ & $1 \cdot 2$
\end{tabular}

The fatty acid compositions of the total lipids, triglycerides and unesterified fatty acids in the rumen contents before and at various times after the infusion of maize oil are given in Table $\mathrm{I}$. Before infusion began, there were only small concentrations of $\mathrm{I} 8: 2$ and $\mathrm{I} 8: \mathrm{I}$ in the lipids of the rumen contents but, immediately after the infusion had ceased, these two unsaturated fatty acids together accounted for about $78 \%$ of the total. During the next hour, the concentrations of $18: 2$ and $18: 1$ decreased and the concentrations of $16: 0$ and $18: 0$ increased. Between the $4^{\text {th }}$ and $24^{\text {th }} \mathrm{h}$ after infusion began, there were further decreases in the concentrations of $18: 2$ and $18: 1$ and a marked increase in the concentration of $18: 0$. In the triglyceride fraction of the rumen contents there was an over-all decrease in the concentration of $18: 2$ and overall increases in the concentrations of both $18: 0$ and $16: 0$. Throughout the experiment, 
I6:0 and $18: 0$ together accounted for 70 to $90 \%$ of the fatty acids in the unesterified fatty acid fraction of the rumen contents. In this fraction the concentration of $18: 2$ remained small but it did increase transiently as a result of the infusion of maize oil.

The fatty acid compositions of the lipid fractions in the abomasal contents before and at various times after the infusion of maize oil are given in Table 2 from which it may be seen that the general pattern of change in fatty acid composition was similar to that observed for the rumen contents. However, as might be predicted from Fig. I $b$, maximum concentrations of $18: 2$ in the total lipid and in the triglyceride fraction of the abomasal contents were not observed until 3-4 h after infusion began. Attention is drawn to the increase in the concentration of $18: 0$ in the total lipid and in the unesterified fatty acid fraction of the abomasal contents between the $4^{\text {th }}$ and $24^{\text {th }} \mathrm{h}$ of the experiment.

Table 2. Fatty acid compositions (major components, weight percentage of the total) of the lipids in the abomasum after the sheep had been given an intraruminal infusion of maize oil

\begin{tabular}{|c|c|c|c|c|c|c|c|c|c|c|c|c|}
\hline \multirow{2}{*}{$\begin{array}{l}\text { Time after } \\
\text { beginning of } \\
\text { infusion } \\
\text { (h) }\end{array}$} & \multicolumn{4}{|c|}{ Total lipid } & \multicolumn{4}{|c|}{ Triglycerides } & \multicolumn{4}{|c|}{ Unesterified fatty acids } \\
\hline & $16: 0$ & $18: 0$ & I $8: 1$ & $18: 2$ & I6:0 & 18:0 & $18: 1$ & $18: 2$ & $16: 0$ & I8:0 & 18: I & I $8: 2$ \\
\hline$\circ$ & $24 \cdot 6$ & $40 \cdot 8$ & $6 \cdot 3$ & $3 \cdot 2$ & & No s & mple & & $23^{\circ} \circ$ & $58 \cdot 5$ & 3.7 & $1 \cdot 2$ \\
\hline I & $27 \cdot 3$ & $35 \cdot 5$ & $8 \cdot 5$ & $6 \cdot 4$ & $25^{.9}$ & $56 \cdot 7$ & 4.9 & 5.7 & $2 \mathrm{I} \cdot 3$ & $57 \cdot 2$ & $6 \cdot 2$ & $4 \cdot 2$ \\
\hline 2 & $27 \cdot 9$ & $30 \cdot 3$ & $9 \cdot 4$ & $12 \cdot 6$ & $28 \cdot 2$ & $9 \cdot 5$ & $24 \cdot 2$ & $35^{\cdot} \mathbf{I}$ & $24 \cdot 2$ & $58 \cdot 5$ & $\mathbf{I} \cdot 6$ & $r \cdot 3$ \\
\hline 3 & $25 \cdot 3$ & $16 \cdot 6$ & $14 \cdot 1$ & $33 \cdot 0$ & I $5 \cdot 1$ & $4 \cdot 4$ & $28 \cdot 8$ & 50.9 & $20 \cdot 4$ & $5^{6 \cdot 8}$ & $3 \cdot 7$ & $2 \cdot 2$ \\
\hline 4 & $19 \cdot 5$ & I $4 \cdot 0$ & $16 \cdot 3$ & $36 \cdot 0$ & $14 \cdot 6$ & $3 \cdot 7$ & $28 \cdot 7$ & $51 \cdot 9$ & $23 \cdot 2$ & $5^{\circ} \cdot 1$ & $6 \cdot 2$ & $3 \cdot 6$ \\
\hline 6 & $16 \cdot 8$ & 20.9 & $21 \cdot 3$ & $29^{\circ} \mathrm{I}$ & 15.8 & 4.3 & $27 \cdot 6$ & $49^{7} 7$ & 18.8 & $60 \cdot 3$ & $4^{\cdot 6}$ & 0.9 \\
\hline 8 & $17 \cdot 2$ & $23^{\circ} 9$ & $22 \cdot 7$ & $26 \cdot 8$ & I4.7 & $3 \cdot 6$ & $27 \cdot 2$ & $49^{\circ} \mathrm{I}$ & $18 \cdot 3$ & $68 \cdot 0$ & $10 \cdot 3$ & $I \cdot 9$ \\
\hline 24 & r6.9 & $4 I \cdot 2$ & 15.9 & 13.9 & I 5.9 & $8 \cdot 8$ & 29.4 & 39.8 & $16 \cdot 1$ & $77 \cdot 5$ & 2.7 & $I \cdot 4$ \\
\hline
\end{tabular}

Infusion of 'linoleic' acid. Thin-layer chromatography showed that the unesterified fatty acid fraction accounted for the major proportion of the lipids in the rumen and abomasal contents throughout the experiment. Consequently, the lipids were not fractionated before fatty acid analyses were carried out, and the results given in Table 3 are the fatty acid compositions of the total lipids extracted from the rumen and abomasal contents before and at various times after the infusion of 'linoleic' acid. In the lipids of the rumen and abomasal contents, the maximum concentrations of I 8:2 occurred $I$ and $3 h$ respectively after infusion began. Between $I$ and $3 \mathrm{~h}$ the concentration of $18: 2$ in the lipids of the rumen decreased and the concentrations of I6:0, $18: 0$ and $18: 1$ increased, but between 3 and $29 \mathrm{~h}$ the concentrations of $16: 0$ and $18: 0$ remained relatively constant whereas the concentration of $18: 2$ continued to decrease and the concentration of $18:$ I continued to increase. Analogous changes occurred in the fatty acid compositions of the lipids of the abomasal contents. Thus, between 7 and $29 \mathrm{~h}$ there was a marked decrease in the concentration of $18: 2$ and a marked increase in the concentration of $18: 1$ but the concentrations of $16: 0$ and $18: 0$ remained relatively unchanged. 


\section{Experiments in vitro}

Vessel no. I (control). Throughout the incubation, the concentration of total unesterified fatty acids in the reaction mixture remained constant at $13.4 \mathrm{mg} / \mathrm{I} 00 \mathrm{ml}$. The composition of the unesterified fatty acid fraction also remained constant during incubation. The fatty acid composition of this fraction was $16: 0,18.6 \% ; 18: 0$, $67.3 \% ; \mathrm{r} 8: 1, \mathrm{x} 2 \cdot 9 \% ; \mathrm{I} 8: 2, \mathrm{I} \cdot 2 \%$. The small concentration of triglyceride fatty acids in the reaction mixture $(2 \mathrm{mg} / \mathrm{r} 00 \mathrm{ml})$ did not change during incubation and the fatty acid composition of the triglycerides was $16: 0,27.4 \% ; 18: 0,15.0 \% ; 18: 1$, $41 \cdot 8 \% ; 18: 2,14 \cdot 9 \%$.

Table 3. Fatty acid compositions (major components, weight percentages of the total) of the total lipids in the contents of the rumen and abomasum after the sheep had been given an intraruminal infusion of 'linoleic' acid

\begin{tabular}{|c|c|c|c|c|c|c|c|c|}
\hline \multirow{2}{*}{$\begin{array}{l}\text { Time after } \\
\text { beginning of } \\
\text { infusion } \\
\text { (h) }\end{array}$} & \multicolumn{4}{|c|}{ Rumen contents } & \multicolumn{4}{|c|}{ Abomasal contents } \\
\hline & I6:0 & I8:0 & I $8:$ I & $18: 2$ & $16: 0$ & I $8: 0$ & $18: \mathrm{I}$ & $18: 2$ \\
\hline 0 & $26 \cdot 9$ & $3^{6 \cdot 2}$ & $8 \cdot 2$ & 2.5 & 24.4 & $36 \cdot 3$ & $7 \cdot 9$ & 0.9 \\
\hline $\mathbf{I}$ & $9^{-1}$ & $4 \cdot 8$ & $18 \cdot 0$ & $67 \cdot 1$ & $19 \cdot 0$ & $25 \cdot 7$ & $12 \cdot 0$ & $19 \cdot 0$ \\
\hline 2 & $10 \cdot 0$ & $6 \cdot 9$ & $19 \cdot 6$ & $59 \cdot 2$ & 14.0 & 14.8 & $16 \cdot 2$ & $37 \cdot 2$ \\
\hline 3 & $12 \cdot 2$ & $8 \cdot 2$ & $2 I \cdot 3$ & 53.9 & 10.7 & $9 \cdot 9$ & $22 \cdot 4$ & $43 \cdot I$ \\
\hline 5 & $12 * 4$ & $9 \cdot 0$ & 23.3 & $50 \cdot 1$ & I I 6 & 10.8 & $25 \cdot 8$ & $37 \cdot 3$ \\
\hline 7 & $13 \cdot 8$ & $9 \cdot 5$ & $27 \cdot 6$ & $44^{\circ} 9$ & I $3 \cdot 3$ & I I I I & 29.5 & $37 \cdot 8$ \\
\hline 9 & $13 \cdot 8$ & $9 \cdot 6$ & $33 \cdot 5$ & $37 \cdot 1$ & $13 \cdot 5$ & $11 \cdot 7$ & $32 \cdot 5$ & $32 \cdot 2$ \\
\hline I I & $13 \cdot 6$ & $9 \cdot I$ & $34^{-1}$ & $35^{\cdot} 5$ & 137 & $12 \cdot 1$ & $35 \cdot 5$ & $27 \cdot 3$ \\
\hline I 5 & $14^{\cdot I}$ & $10 \cdot 1$ & $43^{\circ} \circ$ & $27 \cdot 3$ & $12 \cdot 8$ & $10 \cdot 8$ & $42 \cdot 9$ & 24.7 \\
\hline $2 x$ & $14 \cdot 6$ & 12.4 & 53.4 & 14.4 & $12 \cdot 1$ & 10.0 & $47 \cdot 3$ & $18 \cdot 5$ \\
\hline 29 & 13.7 & I I 4 & 58.9 & $8 \cdot 7$ & 13.9 & $12 \cdot 2$ & $53 \cdot 2$ & $8 \cdot 9$ \\
\hline
\end{tabular}

Vessel no. 2 ('linoleic' acid). During the incubation the concentration of total unesterified fatty acids in the reaction medium remained constant at $53.4 \mathrm{mg} / 100 \mathrm{ml}$ but there were marked changes in the composition of this fraction as incubation proceeded. The concentration of unesterified $\mathrm{I} 6: 0$ in the reaction medium remained constant at about $4.5 \mathrm{mg} / 100 \mathrm{ml}$ but there were marked changes in the concentrations of unesterified $18: 0,18: 1$ and $18: 2$ and these concentrations, corrected for the values found in the control vessel, are shown in Fig. 2. During the first $5 \mathrm{~h}$ of incubation there was a pronounced decrease in the concentration of $18: 2$ and a pronounced increase in the concentration of $18: 1$, but apart from a small increase during the first $\mathrm{I} \cdot 5 \mathrm{~h}$, the concentration of $18: 0$ did not change appreciably over this period. Between 5 and $7 \mathrm{~h}$ the concentration of $18: 2$ continued to decrease and there was a small increase in the concentration of $18: 0$ and a small decrease in the concentration of $18: 1$.

As in vessel no. $\mathrm{r}$, the concentration of triglyceride fatty acids in the reaction medium $(2 \mathrm{mg} / \mathrm{ro0} \mathrm{ml})$ did not change during incubation. The fatty acid composition of this fraction did not change and it was similar to that of the triglyceride fraction in vessel no. I.

Vessel no. 3 (maize oil). As incubation proceeded, the concentration of total unesterified fatty acids in the reaction medium increased and the concentration of triglyceride 


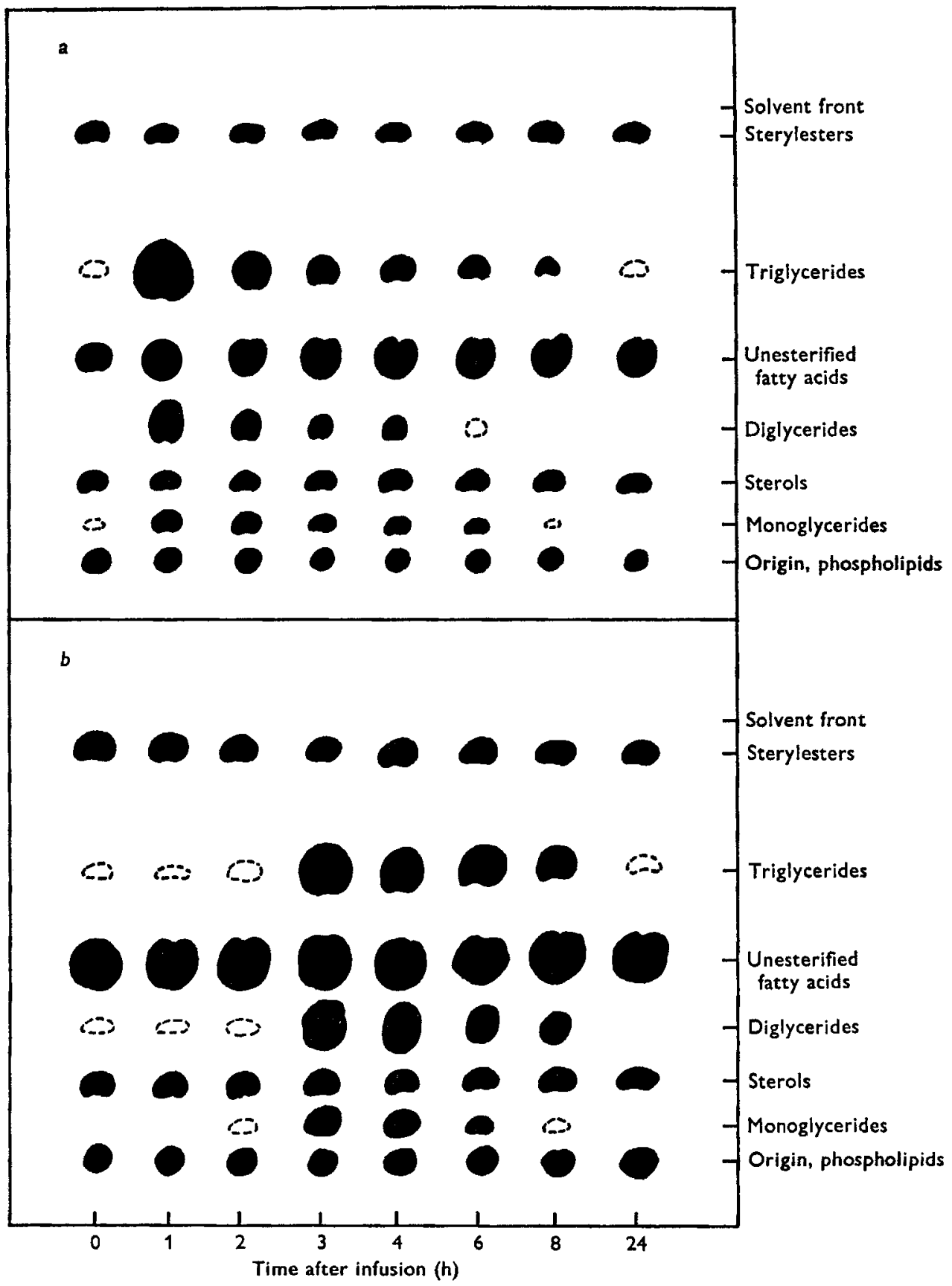

Fig. I. Tracings of thin-layer chromatograms of lipids extracted from the contents of the rumen $(a)$ and abomasum $(b)$ at various times after the infusion of maize oil into the rumen of a sheep. 
fatty acids decreased (Fig. 3). It can be calculated that about $70 \%$ of the maize oil had been hydrolysed by the end of the incubation period. Rather surprisingly, the concentrations of monoglycerides and diglycerides in the reaction mixture did not increase and remained extremely small during the incubation. Throughout the incubation the concentration of unesterified $\mathrm{I} 6: 0$ in the reaction mixture remained constant at $2.7 \mathrm{mg} / 100 \mathrm{ml}$ and the concentration of unesterified $18: 2$ remained constant at $0.5 \mathrm{mg} / \mathrm{r} 00 \mathrm{ml}$. The marked changes in the concentrations of unesterified $\mathrm{r} 8: 0$ and I8: $\mathrm{I}$ in the reaction mixture, after correction with the values obtained in the control vessel, are shown in Fig. 4. During the first $1.5 \mathrm{~h}$ of incubation the concentrations of unesterified $\mathrm{I} 8: 0$ and $\mathrm{I} 8: \mathrm{I}$ both increased to about $5.6 \mathrm{mg} / \mathrm{I} 00 \mathrm{ml}$. However, between $\mathrm{I} \cdot 5 \mathrm{~h}$ and $3 \mathrm{~h}$ there was only a small increase in the concentration of unesterified $\mathrm{I} 8: \mathrm{I}$ whereas there was a pronounced increase in the concentration of unesterified $18: 0$. The concentration of unesterified $\mathrm{I} 8: \mathrm{I}$ did not change after $3 \mathrm{~h}$ but the concentration of unesterified $18: 0$ continued to increase until the end of the experiment.

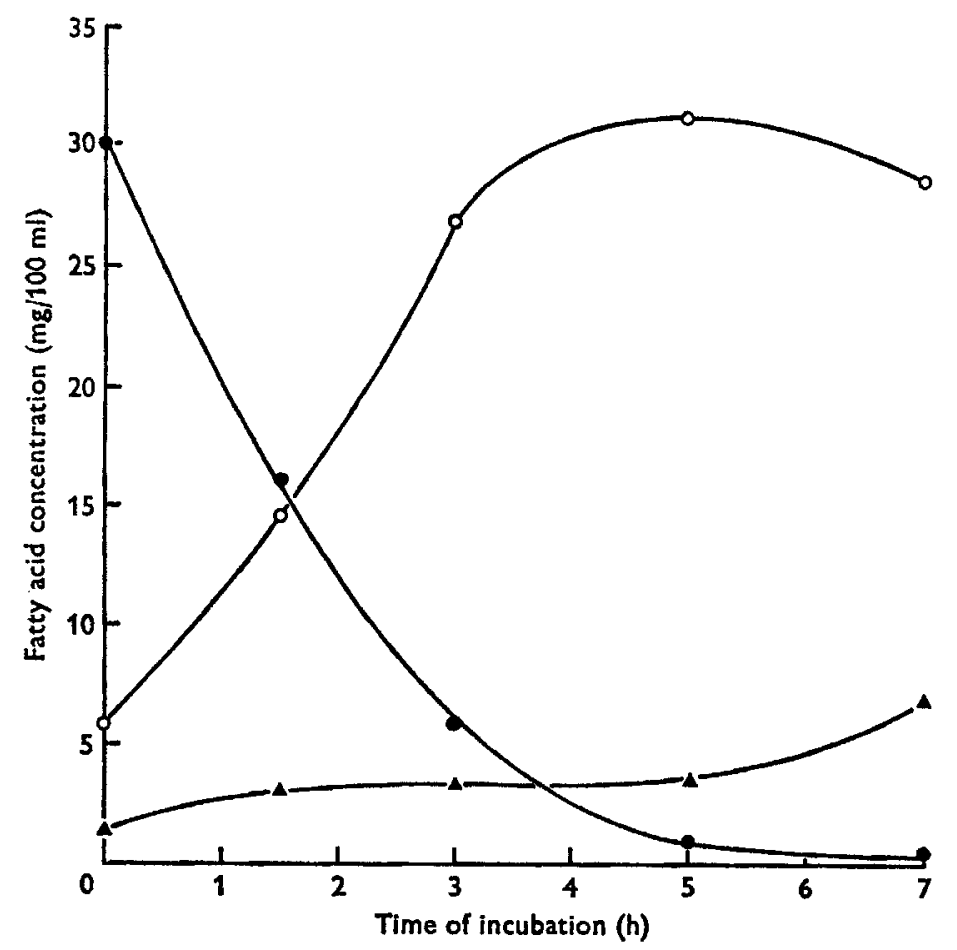

Fig. 2. Changes in the concentrations of individual unesterified fatty acids $(\mathrm{mg} / \mathrm{r} 00 \mathrm{ml}$ of reaction medium) during the incubation of 'linoleic' acid with rumen contents. $\mathrm{O}-\mathrm{O}$, I8: $1 ; 0-18: 2 ; \triangle-\Lambda, 18: 0$.

During the incubation the fatty acid composition of the triglyceride fraction did not change and, when corrected for the values obtained for the triglyceride fraction in the control vessel, it was similar to that of the added maize oil. 


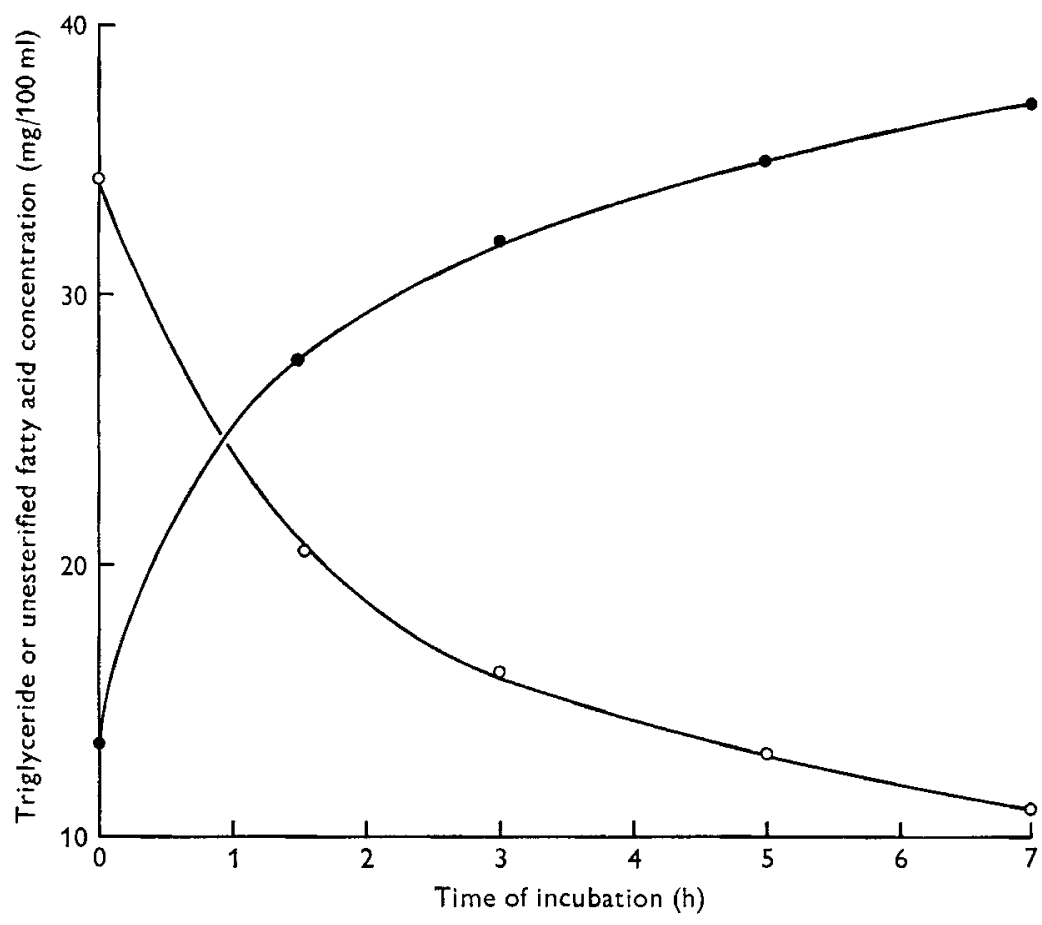

Fig. 3. Changes in the concentrations of triglycerides and total unesterified fatty acids ( $\mathrm{mg} / 100 \mathrm{ml}$ of reaction medium) during the incubation of maize oil with rumen contents. $\mathrm{O} \longrightarrow \mathrm{O}$, triglycerides; $\longrightarrow$, unesterified fatty acids.

\section{DISCUSSION}

The results of these experiments in vivo and in vitro show that maize oil is readily hydrolysed by rumen micro-organisms. Similar results have been reported by Garton, Lough \& Vioque (1961), who also were unable to detect the presence of mono- or di-glycerides as intermediates during the lipolysis of triglycerides by sheep rumen contents in vitro. Garton et al. (I96I) concluded that if mono- and di-glycerides are formed at all during the hydrolysis of triglycerides by rumen micro-organisms, these partial glycerides must have a very transient existence. In this respect, the results of our experiments in vitro are in complete agreement with those of Garton et al. (1961) but the results of our experiments in vivo show that the hydrolysis of maize oil in the rumen of a sheep resulted in the formation of mono- and di-glycerides (Fig. I $a, b$ ). The differences between these findings in vivo and those in vitro may be simply due to differences in the ratios of the amounts of substrate to the amounts of rumen microorganisms under the different experimental conditions. The results from the experiment in which maize oil was infused into the rumen of the sheep (Table I) and that in which maize oil was incubated with rumen contents in vitro (Fig. 4) showed that the hydrolysis of the triglyceride resulted in the production of little or no unesterified I $8: 2$. This must indicate that, under these conditions, $18: 2$ was hydrogenated as rapidly as it was released from the glyceride molecules. The increase in the concentration 
of $18: 0$ in the unesterified fatty acids in the rumen contents after the infusion of maize oil ('Table I) and the pronounced increase in the concentration of unesterified 18:0 in the medium during the incubation of maize oil with rumen contents (Fig. 4) clearly show that the $18: 2$ liberated by lipolysis was efficiently hydrogenated to $18: 0$, since in neither instance was there any accumulation of $18: \mathrm{I}$. The increase in the concentration of unesterified $\mathrm{I} 8: \mathrm{I}$ in the reaction medium during the first $\mathrm{I} \cdot 5 \mathrm{~h}$ of incubation of maize oil with rumen contents could have been due to the liberation of the $\mathrm{I} 8$ : I contained in the maize oil. Garton et al. ( $196 \mathrm{I}$ ) have considered the possibility that hydrogenation of unsaturated fatty acids by rumen micro-organisms might take

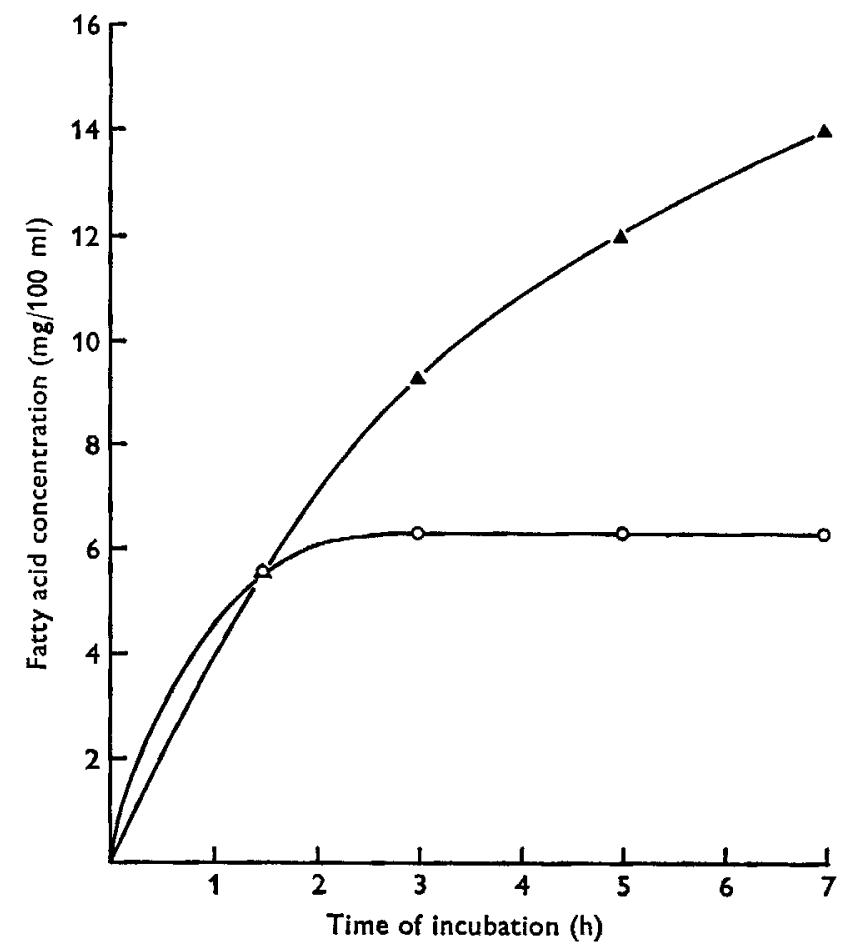

Fig. 4. Changes in the concentrations of individual unesterified fatty acids $(\mathrm{mg} / \mathrm{1} 00 \mathrm{ml}$ of reaction medium) during the incubation of maize oil with rumen contents. $\mathrm{O}-\mathrm{O}, \mathrm{I} 8: \mathrm{I}$; $\Delta-\Delta$, I $8: 0$.

place while the acids are still esterified with the hydroxyl groups of glycerol. In this respect, it was of interest to note that after the infusion of maize oil into the rumen there was a progressive increase in the concentration of $18: 0$ and a decrease in the concentration of $18: 2$ in the triglyceride fraction of the rumen contents (Table 1 ); however, there was also an increase in the concentration of $16: 0$. The fact that the largest increases in the concentrations of $16: 0$ and $18: 0$ and the largest decrease in the concentration of $18: 2$ in the triglycerides of the rumen contents occurred between 8 and $24 \mathrm{~h}$ after infusion began (Table I) suggests that these changes in the fatty acid composition were due to the fact that triglycerides derived from the diet and from the micro-organisms formed an increasing proportion of the total triglycerides that remained in the rumen towards the end of the experiment. 
When 'linoleic' acid was incubated with rumen contents there was a fairly rapid hydrogenation of $I 8: 2$ but the main product of this reaction was $I 8: I$ (Fig. 2). The concentration of unesterified $18: 0$ in the reaction medium remained small until the incubation had progressed for $5 \mathrm{~h}$; thereafter it appeared that hydrogenation of $\mathrm{I} 8: \mathrm{I}$ to $18: 0$ occurred to a slight extent (Fig. 2). The results obtained from the experiment in vitro (Fig. 2) are entirely consistent with those obtained from the experiment in vivo (Table 3). These findings provide an explanation for the previous observations (Noble et al. 1969) that the infusion of maize oil into the rumen of sheep was followed by a marked increase in the $18: 0$ content of the plasma triglycerides whereas the intraruminal infusion of 'linoleic' acid is followed by a marked increase in the $18: 1$ content of the plasma triglycerides.

It is possible that when maize oil is infused into the rumen or is used as a substrate for rumen micro-organisms in experiments in vitro, the rate of hydrolysis is such that the liberated $18: 2$ never saturates the hydrogenating system. Under these conditions, hydrogenation proceeds efficiently with the production of $18: 0$ and little or no intermediates. When 'linoleic' acid is infused into the rumen or is used as a substrate in experiments in vitro, it is possible that the initial high concentration of $18: 2$ inhibits some step in the hydrogenation mechanism. According to Polan, McNeill \& Tove (1964), the hydrogenation of $18: 2$ to $18: 0$ by rumen micro-organisms involves two separate systems, one that converts $18: 2$ into $18: I$ and the other that converts I8: I into 18:0. Polan et al. (1964) obtained some evidence that high concentrations of $18: 2$ completely inhibit the conversion of $\mathrm{I} 8: \mathrm{I}$ into $\mathrm{I} 8: 0$ by the second system. Our findings would be entirely consistent with such an inhibition.

The authors thank Miss G. Breckenridge, Miss E. Skinner, Miss I. Fisher and Mr. J. McDill for their skilled technical assistance.

\section{REFERENCES}

Czerkawski, J. W. (1966). Br. F. Nutr. 20, 833 .

Czerkawski, J. W. \& Breckenridge, G. (1969). Br. F. Nutr. 23, 5 I.

Garton, G. A., Lough, A. K. \& Vioque, E. (1961). F. gen. Microbiol. 25, 215.

McDougall, E. I. (1 948). Biochem. $\mathcal{F} .43,99$.

Moore, J. H., Noble, R. C. \& Steele, W. (I968). Br. F. Nutr. 22, 68I.

Moore, J. H. \& Williams, D. L. (1963). Can. F. Biochem. Physiol. 41, I82 I.

Noble, R. C., Steele, W. \& Moore, J. H. (1969). Br. F. Nutr. 23, 709.

Polan, C. E., McNeill, J. J. \& Tove, S. B. (1964). F. Bact. 88, 1056. 